ISSN No. 0974-035X

An Indexed, Refereed \& Peer Reviewed Journal of Higher Education

Towards Excellence

UGC-HUMAN RESOURCE DEVELOPMENT CENTRE,

GUJARAT UNIVERSITY, AHMEDABAD, INDIA

\title{
FACTORS AFFECTING JOB INVOLVEMENT IN TELECOM SECTOR: A RESEARCH AGENDA
}

\section{Ms. Radhika Gandhi}

\begin{abstract}
:
It is very much essential for employees to be highly involved to stay well motivated and committed as they are considered to be the most important asset for any organization which serves as key to quality and productivity improvements. The current research study is an attempt to develop a conceptual framework of Job Involvement (JI) as a dependent variable and Work Motivation, Employee Personality, Training, Job Characteristics \& Human Resource Development (HRD) Climate altogether as Independent Variables influencing JI especially for organizations operating in Telecom sector.
\end{abstract}

Keywords: Job Involvement, Work Motivation, Employee Personality, Training, Job Characteristics, HRD Climate, Telecom sector 


\section{INTRODUCTION}

Employees today are considered the strongest pillar and the most valuable asset that contributes significantly to the success and prosperity of any given organization. In a service industry such as telecom sector, organizations face the challenges to provide quality customer services keeping them happy, content and satisfied. Especially in telecom sector, factors such as work motivation, employee personality, training, job characteristics and HRD climate play a very important role when it comes to dealing with employees. Most of the new generation employees desire to work in companies that can actively listen and embrace their ideas. To accommodate them, most companies have relinquished their centralized control management with the hope of promoting flexibility and decisiveness as well as subsequent improvement in individual and organizational performance (Hung 2008). Ho, (2006) in his research about job involvement defined it as the individual's belief towards his or her present job. Khalid and Rashid Rehman, (2011) described job involvement as motivation to carry out work and it is highly compatible between personal and organizational goals, which stimulate motivation among the employees to generate positive work outcomes.

\section{CONCEPTUAL FRAMEWORK OF JOB INVOLVEMENT}

In the Conceptual framework, factors influencing Employee's Job Involvement especially in telecom sector are looked at. However, focus is only on the major factors that are supported by most researchers and scholars. As a result, chosen factors are motivation, personality, training, job characteristics and HRD Climate.

\subsection{Relevant Theoretical Models}

Relevant theoretical models for understanding the relationship between job involvement and its antecedent and outcome variables are as follows: (1) Expectancy Theory (Vroom. 1964), (2) Integrated Theory (Rabinowitz\& Hall, 1977), (3) the Motivational Approach (Kanungo, 1982), (4) Causality Theory (Brown, 1996), (5) Multidimensional model Yoshimura(1996) and (6) Theoretical Model from Lodahl and Kejner.

\subsubsection{Expectancy Theory}


According to Vroom's Expectancy Theory (1964), administrators should make good use of individual expectancy to inspire employees. This theory is based on the fundamental concept that an individual's action is determined by likely expected results as well as the relationship between the results and the action adopted.

\section{Figure 2.1:}

Expectancy<inducement offered by organization =job involvement

Expectancy $>$ inducement offered by organization=job involvement

The Expectancy Theory Model of Vroom (1964).

\subsubsection{Integrated Theory Model}

Rabinowitz and Hall (1977) developed three major conceptualizations by reviewing and integrating previous research in the field as a base. According to them, job involvement can be classified into three categories of working variables; (1) the dispositional approach held by the individual, (2) the situation determined approach held and (3) the influence of the interaction between these approaches. In this model, both dispositional and situational variables have been equally important in explaining job involvement. The dispositional approach states dependency of job involvement on individual personalities.

\section{Figure 2.2:}

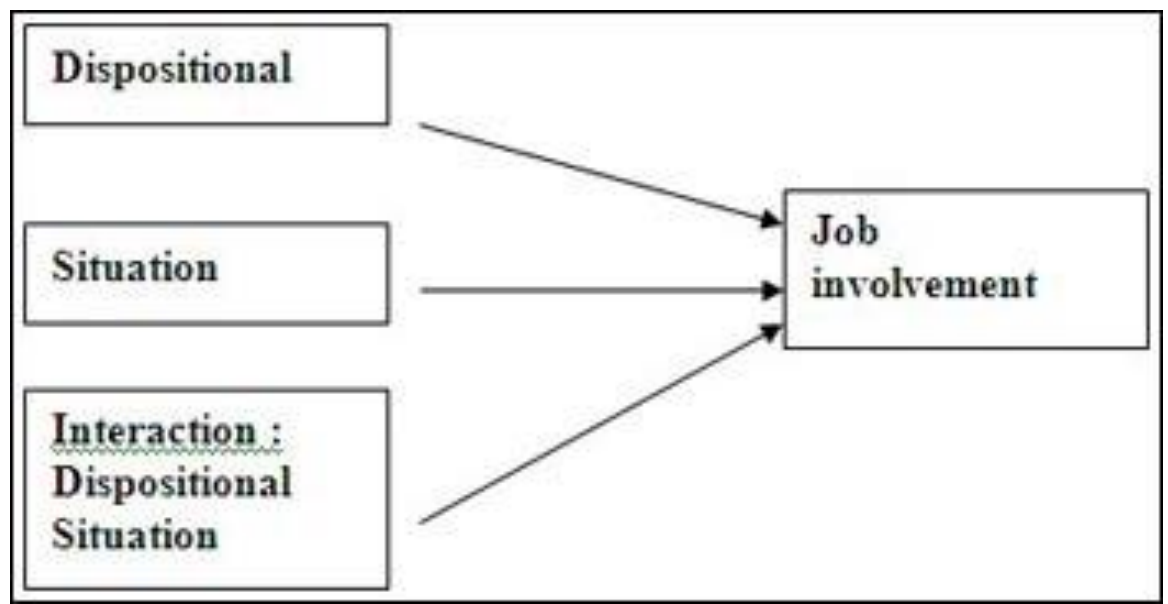

The Job Involvement Theory Model of Rabinowitz and Hall (1977). 


\subsubsection{Motivational Approach}

The motivational approach developed by Kanungo $(1979,1982)$ shows integration between different approaches to job involvement, including both psychological and sociological factors by using the basic concept that both the potential for personal socialization experience and the likelihood of the work environment to satisfy personal demand affects Job Involvement to a greater extent.

\subsubsection{Causality Theory Model}

The causality theory of job involvement theory proposed by Brown (1996) integrates the findings of previous research and has been developed including antecedents (personality variables-concept of work ethic), the pivotal mediator role of job involvement, and its consequences such as organizational commitment.

\subsubsection{Multi-dimensional model of job involvement}

Yoshimura (1996) presented a concept of a multidimensional model of job involvement in which he stated that job involvement consists of three dimensions viz., emotional, cognitive and behavioral. Emotional indicates the extent of a worker's interest in his/her job or his/her likings towards the job, Cognitive indicates the extent of a worker's desire to participate in his/her job related decision making or the importance of a job in his or her whole life and behavioral indicates the frequency of a worker's extra-role behavior such as taking an evening class to enhance job related skills or thinking about the job after leaving the office or staying back at office to finish a task even after office hours.

Figure 2.3:

\begin{tabular}{|l|l|}
\hline $\begin{array}{l}\text { Emotional Job } \\
\text { Involvement }\end{array}$ & $\begin{array}{l}\text { Attachment } \\
\text { Interest } \\
\text { liking }\end{array}$ \\
\hline Cognitive Job & Psychological state \\
Involvement & $\begin{array}{l}\text { Self-esteem } \\
\text { Active participation }\end{array}$ \\
\hline Behavioral Job & Behavioral intention \\
Involvement & Extra-role behavior \\
Voluntary learning
\end{tabular}

Yoshimura's Multi-dimensional model of Job Involvement (1996) 
The above model helps to understand the evolution of job involvement and changes in the concept over time.

\subsubsection{Theoretical Model from Lodahl and Kejner}

Govender and Parumasur, (2010) held that job involvement incorporates four sub-dimensions: (1) response to work - as per expectancy theory of Lodahl and Kejner, employees response to their work (2) expressions of being job involved (3) sense of duty towards work and (4) feelings about unfinished work and absenteeism.

\subsection{Conceptual Framework}

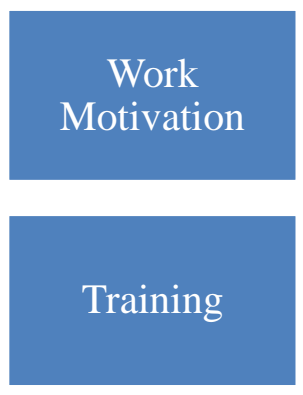

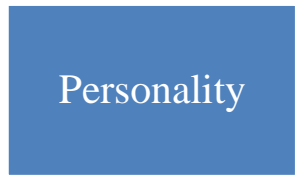

Job

characteristics

\section{HRD Climate}

Independent Variables

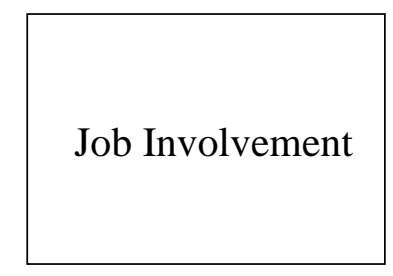

Dependent Variable

\subsubsection{Independent Variable - Motivation}

It is critical to identify the factors affecting employees' job involvement as employee's motivation is a complicated matter. Based on the study of Mollins (cited in Govender and Parumasur 2010), motivation directly influences employee's job involvement. Armstrong (2006) revealed that intrinsic motivation has a strong and long-term effect on employees due to its inherent nature which is not enforced by the management, and thus it is the best form of motivation. Jordan (2009) stated that motivation 
programmes generally fail due to lack of diversification of the rewards. Schoeffler (2005) said some organizations focuses on their broad targets instead of focusing on individual people or teams.

\subsubsection{Independent variable-Employee personality}

Employee personality mainly describes and predicts human behavior rather than showcasing behavioral changes or development. Tupes and Christal (1961) proposed five factors (extroversion, neuroticism [emotional stability], agreeableness, conscientiousness, and culture) that matched McDougall's views. Barrick and Mount's (1991) meta-analysis confirmed that five factors neuroticism (emotional stability), extroversion, openness, agreeableness, and conscientiousness have been in use by most of the researchers then for the study.

\subsubsection{Independent Variable - Training}

Training and development is important for the implementation of Human Resource Management (HRM) and Total Quality Management (TQM) as it enhances the employees' job involvement, ease the updating of skills, increase the sense of belonging, benefit one's well-being, maximize commitment towards organization and build the organization's competitiveness. Bartlett (2001), stated that a training program which is designed to advance the performance on central aspects of their existing job will lead to a positive relation between a job involvement and training-related outcomes and vice-versa when the focus of the training program is at more peripheral aspect of employees' present job. He further, divided the training concept into six sub-variables consisting of participation in training, perceived access to training, motivation to learn from training, perceived benefits from training, perceived support for training, and job organizational tenure.

\subsubsection{Independent Variable - Job Characteristics}

It is a known fact that high motivating job characteristics like skill variety, task significance, task identity, autonomy, and feedback are positively related to employees' job involvement. Job involvement can be influenced by job characteristics because employees' internal motivation may be enhanced by core job characteristics. Overall, the model suggests that motivating job characteristics lead to higher employees' motivation, high-quality performance, higher job satisfaction, lower absenteeism, as well as low labor turnover subsequently leading to high level of employees' job involvement.

\subsubsection{Independent Variable - HRD Climate}


Human Resource Development (HRD) is a process by which the employees of an organization acquire and develop their capabilities and inner-potentials to perform various functions or duties assigned to them by the organization. It ensures developing both 'self' and the 'organization' and helps in developing an organization culture to achieve the pre-determined objectives. An optimal level of 'Developmental Climate' is essential to facilitate HRD. D. Yuvaraj \& Dr. P. Gurusamy (2013) explored the relationship between HRD Climate and Job Satisfaction amongst employees which showed that a good HRD Climate prevails in the organization. Y. Benazir \& V. Devi Priya (2014) examined the influence of HRD Climate on employee's performance and determined the continuous critical objectives and performance standards for each job.

\subsubsection{Dependent Variable - Job Involvement}

The earlier concept of job involvement was originally developed by Lodahl and Kejner in 1965 (Khan and Nemati, 2011). They defined job involvement as the degree to which a person's self-esteem was influenced by his or her work performance. Later on, this concept was elaborated by Kanungo (Ho, 2006) in which he defined job involvement as the individual's belief towards his or her present job and also stated that job involvement acts as a catalyst to satisfy the individual present needs. Hung (2008) stated that job involvement is a fulfillment of one's cognitive needs assisting him or her to work harder and boost up his or her performance. Rowold (2008) proved that technical training is able to cultivate employees' job involvement along with updating employees' knowledge, skills, and abilities (KSA). Finally, Brown (as cited in Chughtai, 2008) argued that dimensions of job characteristics, such as job autonomy, task identity, skill variety, task significance, feedback and also supervisory behaviors, including participative decision making, leader consideration, and amount of communication have a significant linkage to job involvement.

\section{CONCLUSION}

Telecom sector is witnessing a rapidly changing environment; may it be economical, structural or technological. Due to such changes, this sector is a part of a tough level of competitiveness in the industry. In order to survive this situation, telecom organizations will have to boost up their employees to perform better thereby having high level of Job Involvement. All those independent variables shown in the conceptual framework are important because they help increase the level of JI. This study provides a better understanding of the factors affecting employees' job involvement. Hence, any 
organization especially operating in Telecom Sector is advised to utilize these predictor variables all together and not as independent entities to positively enhance the JI as well as to better the overall organizational performance, growth in business and in personal development of employees. This will help reduce turnover rate, low customer service delivery and declining performance.

\section{REFERENCES}

- Akhtar, Z., \& Udham, S. (2010), Job Involvement: A Theoretical Interpretation in Different Work Settings. IndianMBA.com. Retrieved December 8, 2015

- Armstrong M, (2006): A handbook for Human Resource Management Practice, Kogan Page Ltd Publishers. 10th Edition

- Barrick, M.R. and Mount, M.K. (1991), The Big Five personality dimensions and job performance: A Meta-analysis, Personnel Psychology, 44, 1 - 26.

- Benazir Y. and Devi Priya V. (2014), "A Study on the HRD Climate and its Influence on the Performance among the Employees", International Journal of Research and Development, Volume-2, Issue-4, 2319-5479

- Bhatt K. and Mehta T. (2013), "Effect of HRD Climate in Private Sectors Banks at Bhavnagar District", International Journal of Advance Research in Computer Science and Management Studies, Volume 1, Issue 7, pg. 408-413

- Brown S. and Leigh T. (1996), "A New Look at Psychological Climate and Its Relationship to Job Involvement, Effort, and Performance", Journal of Applied Psychology Vol. 81, No. 4, 358368

- Brown, S.P. (1996), “A Meta-Analysis and Review of Organizational Research on Job Involvement", Psychological Bulletin, 120(2): 235-55.

- Chughtai, A. A. (2008), Impact of Job Involvement on In-Role Job Performance and Cynthia, Organizational Citizenship Behavior. Institute of Behavioral and Applied Management, 9(2), 169-183.

- Farhan Akhtar, M., Ali, K., Sadaqat, M. S., \& Hafeez, S. (2011), Extent of Training in Banks and its Impact on Employees' Motivation and Involvement in Job. Interdisciplinary Journal of Contemporary Research in Business. 
- Govender, S. \& Parumasur, S. B. (2010), The Relationship between Employee Motivation and Job Involvement. SAJEMSNS, 13(3), 237-253.

- Hao, Z., \& Seibert, S. E. (2006), The Big Five Personality Dimensions and Entrepreneurial Ho, Status: A Meta-Analytical Review. Journal of Applied Psychology, 91 (2), 259-271.

- Hung, L. M. (2008). Research on How Training Influences Administrative Staff Job Involvement and Organizational Commitment. The Journal of Human Resource and Adult Learning, 4(2), 115-121.

- Ishfaq, A., \& Talat, I. (2011). Decoding the Relationship between Employee's Jobs Related Behaviors: A Study of Telecom Sector of Pakistan. International Journal of Business and Social Science, 2(8), 244-252.

- Kanungo, R. (1982). Measurement of job and work involvement. Journal of Applied Psychology.

- Khalid, A., \& Rashid Rehman, R. (2011). Effect of Organizational Change on Employee Job Involvement: Mediating Role of Communication, Emotions and Psychological Contract. Information Management and Business Review,

- Pinder, C. C. (1998). Work Motivation in Organizational Behavior. Upper Saddle River, NJ: Prentice-Hall.

- Rabinowitz, S. and Hall, D.T., "Organizational research on job involvement", Psychological Bulletin, 1977, 84, 365-288.

- Tupes, E.C. and Christal, R.E. (1961) Recurrent personality factors based on trait rating, Report ASD-TR-61-97, Lackland Air Force Base, TX: U. S. Air Force.

\section{Ms. Radhika Gandhi}

\section{Ph.D. Scholar [Gujarat University]}

\section{Assistant Professor [Gujarat Technological University]}

\section{E-mail: 19.rgandhi@gmail.com}

